\title{
COVID-19 Antibody Tests and their Limitations
}

Guoqiang Lius๋ ${ }^{\S}$ and James F. Rusling ${ }^{* \dagger \ddagger \#}$

$\S$ Medical College, Jiaxing University, 118 Jiahang Road, Jiaxing, Zhejiang Province, China

${ }^{\dagger}$ Department of Chemistry, University of Connecticut, 55 North Eagleville Road, Storrs, CT 06269, USA

‡Department of Surgery and Neag Cancer Center, UConn Health, Farmington, CT 06232, USA

${ }^{\ddagger}$ Institute of Materials Science, University of Connecticut, 97 N. Eagleville Road, Storrs, CT 0626, USA

\#School of Chemistry, National University of Ireland Galway, University Road, Galway, Ireland

*Corresponding author: James.Rusling@Uconn.edu

\section{Table of Contents}

Table S1. Performance of immunoassays for binding antibodies. ..................................................... 2

Table S2. The time of detecting antibodies after symptom onset. .................................................. 14

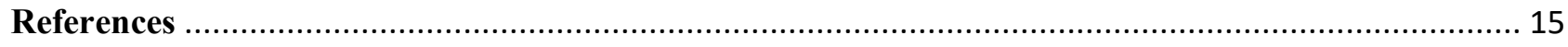


Table S1. Performance of immunoassays for binding antibodies.

\begin{tabular}{|c|c|c|c|c|}
\hline Antibody & Antigen & Method & $\begin{array}{l}\text { Sensitivity or positive } \\
\text { coincidence with RT-PCR }\end{array}$ & $\begin{array}{l}\text { Specificity or negative } \\
\text { coincidence with RT-PCR }\end{array}$ \\
\hline \multirow[t]{20}{*}{$\operatorname{IgG}$} & $\mathrm{N}$ & ELISA & $23 \%(15 / 65)^{1}$ & $88.7 \%(47 / 53)-100 \%$ \\
\hline & & & $57.8 \%(26 / 45)^{2}$ & $(53 / 53)^{9}$ \\
\hline & & & $64.7 \%(112 / 167)^{3}$ & $92.5 \%(49 / 53)^{16}$ \\
\hline & & & $66.7 \%(30 / 45)^{4}$ & $95.0 \%(57 / 60)^{8}$ \\
\hline & & & $69 \%(45 / 65)^{5}$ & $98.5 \%(202 / 205)^{17}$ \\
\hline & & & $70.1 \%(150 / 214)^{6}$ & $99.0 \%(195 / 197)^{3}$ \\
\hline & & & $77.9 \%(162 / 208)^{7}$ & $100 \%(35 / 35)^{4}$ \\
\hline & & & $83.3 \%(55 / 66)^{8}$ & $100 \%(64 / 64)^{1}$ \\
\hline & & & $86.4 \%(19 / 22)-100 \%(22 / 22)^{9}$ & $100 \%(70 / 70)^{13}$ \\
\hline & & & $88.8 \%(71 / 80)^{10}$ & $100 \%(100 / 100)^{6.10}$ \\
\hline & & & $88.89 \%(88 / 99)^{11}$ & $100 \%(152 / 152)^{2}$ \\
\hline & & & $81 \%(13 / 16)$ on DPSO $0,100 \%$ & \\
\hline & & & $(16 / 16)$ on DPSO $5^{12}$ & \\
\hline & & & $90 \%(18 / 20)^{13}$ & \\
\hline & & & $93.8 \%(61 / 65)^{14}$ & \\
\hline & & & $94 \%(15 / 16) \geq 14 \mathrm{DPSO}^{15}$ & \\
\hline & & & $100 \%(22 / 22)^{16}$ & \\
\hline & & LFIA or ICG & $61.76 \%(21 / 34)^{18}$ & $99.5 \%(208 / 209)^{10}$ \\
\hline & & & $84.3 \%{ }^{19}$ & $100 \%(40 / 40)^{19}$ \\
\hline & & & $86.3 \%(69 / 80)^{10}$ & \\
\hline
\end{tabular}


Table S1. Continued.

\begin{tabular}{|c|c|c|c|c|}
\hline Antibody & Antigen & Method & $\begin{array}{l}\text { Sensitivity or positive } \\
\text { coincidence with RT-PCR }\end{array}$ & $\begin{array}{l}\text { Specificity or negative } \\
\text { coincidence with RT-PCR }\end{array}$ \\
\hline \multirow[t]{20}{*}{$\mathrm{IgG}$} & $\mathrm{N}$ & MCLIA or & $8.8 \%<7$ DPSO, $40.5 \% 7-13$ & $97.5 \%(78 / 80)^{1}$ \\
\hline & & CMIA & DPSO, 81.0\% 14-20 DPSO, & $99.4 \%(152 / 153)^{23}$ \\
\hline & & & $84.4 \% \geqslant 21 \mathrm{DPSO}^{20}$ & $100 \%(35 / 35)^{4}$ \\
\hline & & & $38 \%(29 / 76)^{21}$ & $100 \%(795 / 795)^{21}$ \\
\hline & & & $61.5 \%(16 / 26) \dagger^{22}$ & $100 \%{ }^{24}$ \\
\hline & & & $77.8 \%(35 / 45)^{4}$ & \\
\hline & & & $82.3 \%(65 / 79)^{1}$ & \\
\hline & & & $93.8 \%(45 / 48) \geq 14 \mathrm{DPSO}^{23}$ & \\
\hline & & & $53.1 \%(\mathrm{CI}, 39.4 \%$ to $66.3 \%)$ at 7 & \\
\hline & & & DPSO, $82.4 \%$ (51.0\% to $76.4 \%)$ & \\
\hline & & & at 10 DPSO, $96.9 \%(89.5 \%$ to & \\
\hline & & & $99.5 \%$ ) at 14 DPSO, and $100 \%$ & \\
\hline & & & $(95.1 \%$ to $100 \%)$ at $17 \mathrm{DPSO}^{24}$ & \\
\hline & & MFIA & $0 \%(0 / 5)-40 \%(2 / 5)<10$ DPSO, & $99 \%(133 / 134)$ in saliva, \\
\hline & & & $89 \%(25 / 28)-100 \%(28 / 28) \geq 10$ & $97 \%(109 / 112)-98 \%$ \\
\hline & & & DPSO in saliva; $15 \%$ (14/92)- & $(110 / 112)$ in serum ${ }^{25}$ \\
\hline & & & $22 \%(20 / 92)<10$ DPSO, $78 \%$ & \\
\hline & & & $(81 / 104)-90 \%(94 / 104) \geq 10$ & \\
\hline & & & DPSO in serum ${ }^{25}$ & \\
\hline & $\Delta \mathrm{N}-\mathrm{NP}$ & ELISA & $100 \%(20 / 20)>$ DPSO $8^{13}$ & $100 \%(70 / 70)^{13}$ \\
\hline
\end{tabular}


Table S1. Continued.

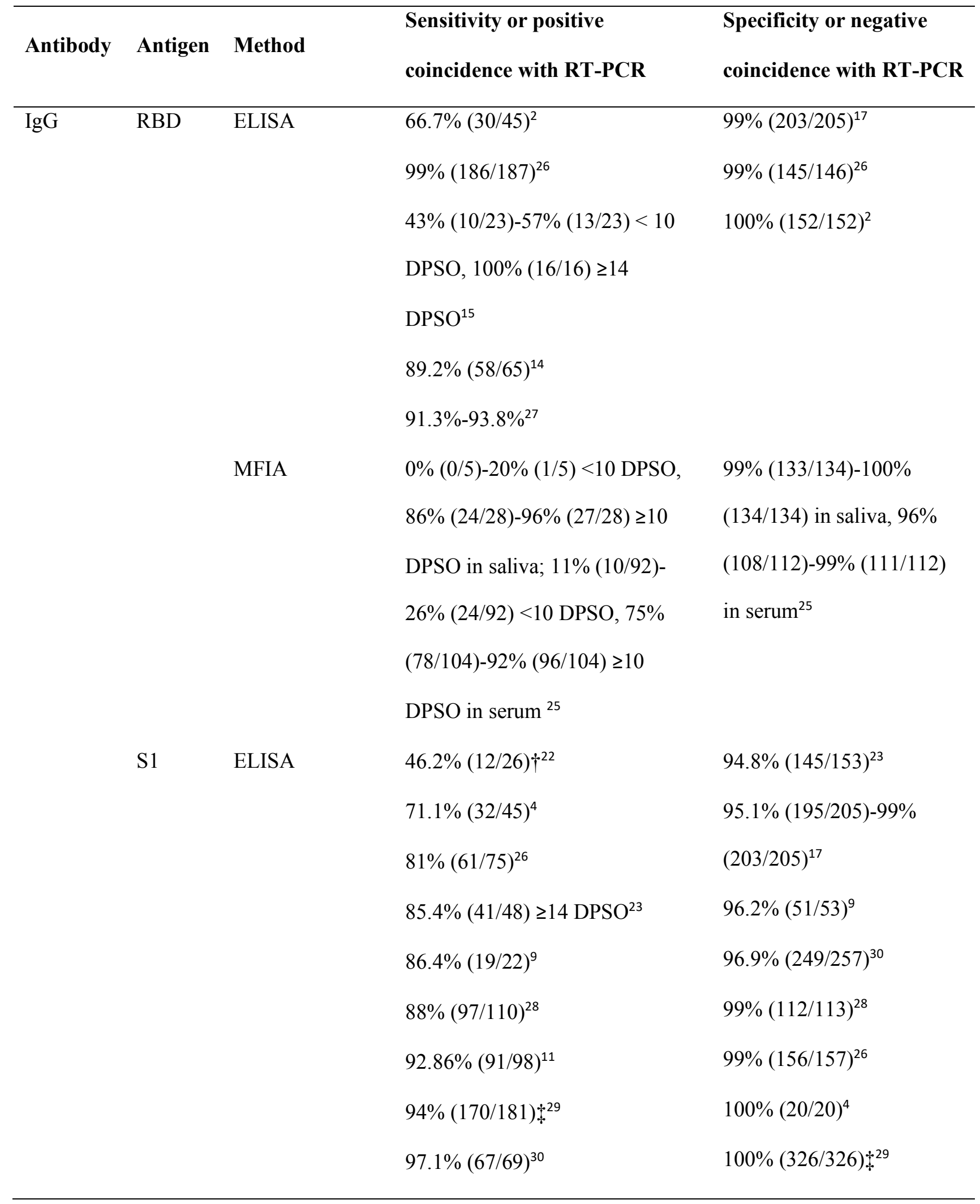


Table S1. Continued.

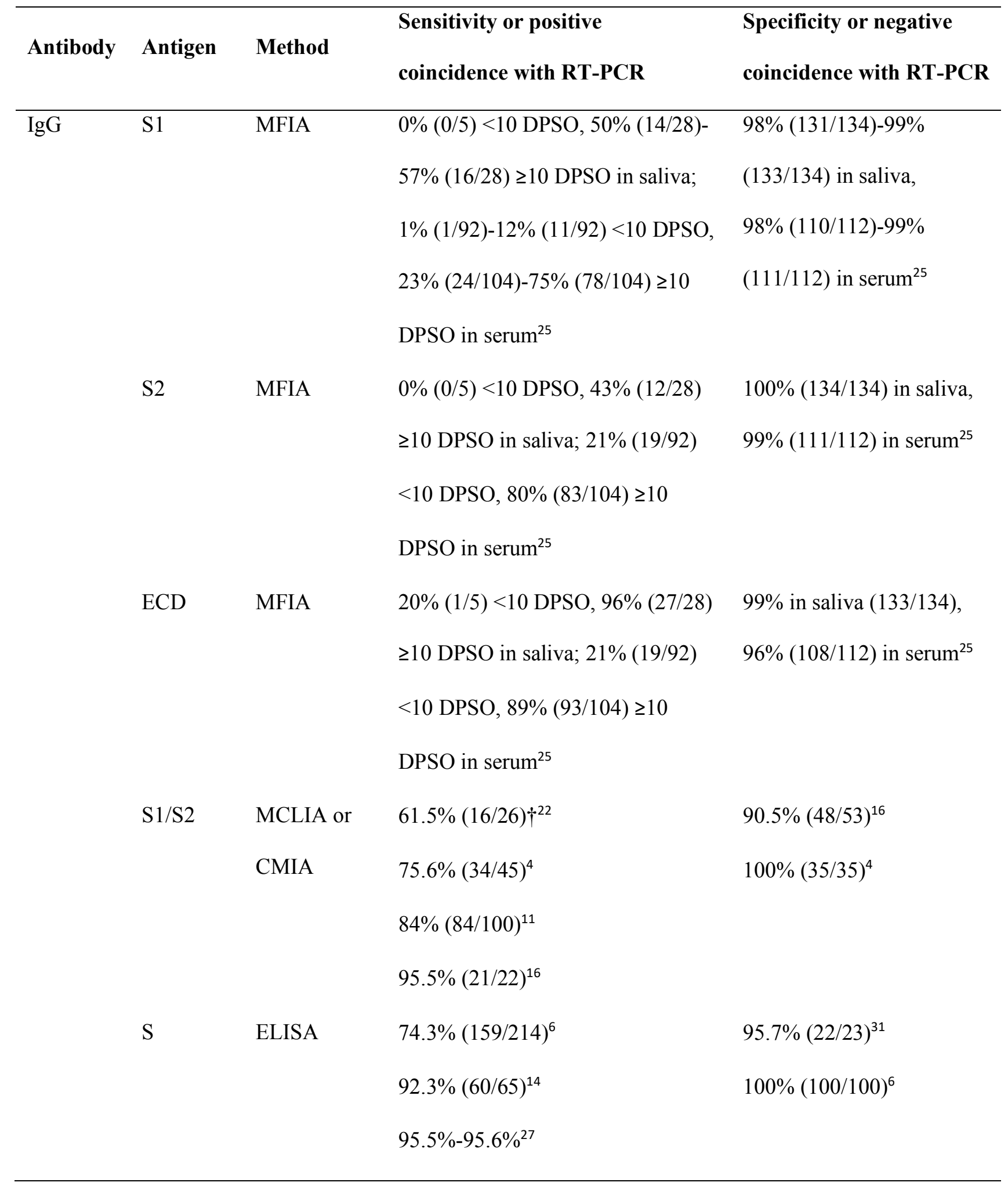


Table S1. Continued.

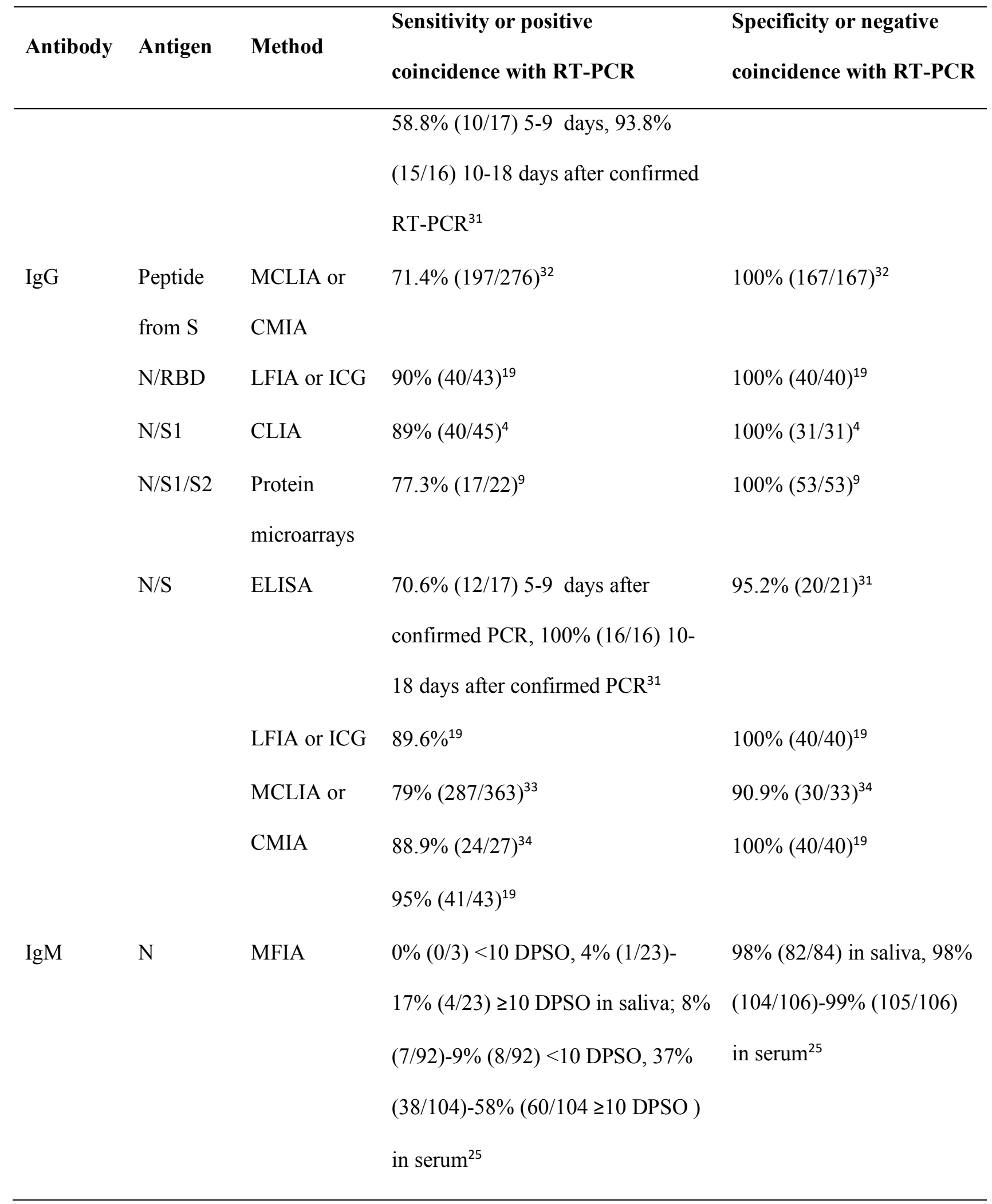


Table S1. Continued.

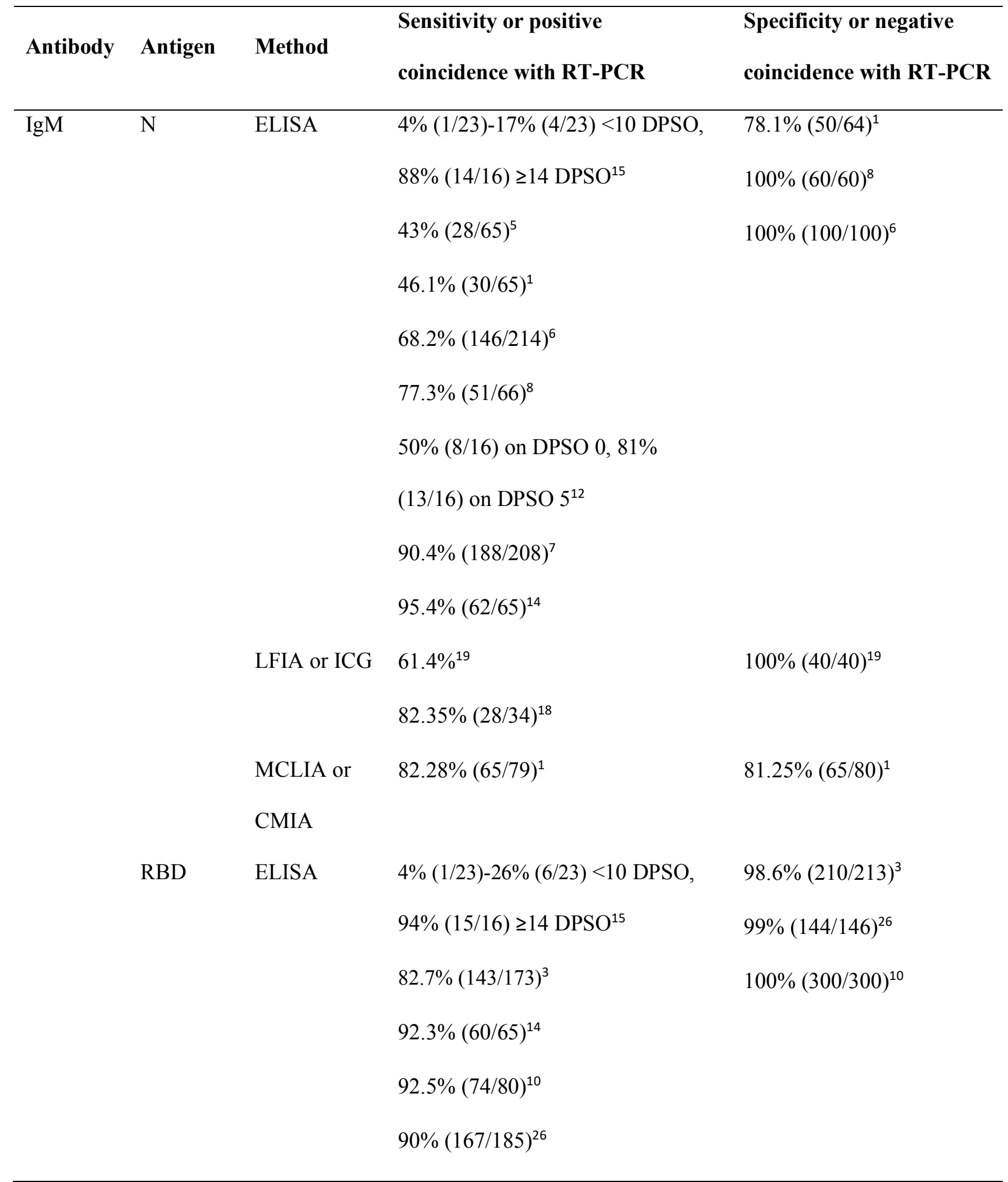


Table S1. Continued.

\begin{tabular}{|c|c|c|c|c|}
\hline Antibody & Antigen & Method & $\begin{array}{l}\text { Sensitivity or positive } \\
\text { coincidence with RT-PCR }\end{array}$ & $\begin{array}{l}\text { Specificity or negative } \\
\text { coincidence with RT-PCR }\end{array}$ \\
\hline IgM & RBD & $\begin{array}{l}\text { LFIA or ICG } \\
\text { MCLIA or } \\
\text { CMIA } \\
\text { MFIA }\end{array}$ & $\begin{array}{l}0 \%(0 / 3)<10 \text { DPSO, } 17 \%(4 / 23)- \\
35 \%(8 / 23) \geq 10 \text { DPSO in saliva; } \\
21 \%(19 / 92)-37 \%(34 / 92)<10 \\
\text { DPSO, } 80 \%(83 / 104)-93 \%(97 / 104) \\
\geq 10 \text { DPSO in serum }{ }^{25}\end{array}$ & $\begin{array}{l}96 \%(81 / 84)-98 \%(82 / 84) \\
\text { in saliva, } 96 \%(102 / 106)- \\
99 \%(105 / 106) \text { in serum }{ }^{25}\end{array}$ \\
\hline & S1 & MFIA & $\begin{array}{l}0 \%(0 / 3)<10 \text { DPSO, } 4 \%(1 / 23)- \\
65 \%(15 / 23) \geq 10 \text { DPSO in saliva; } \\
2 \%(2 / 92)-25 \%(23 / 92)<10 \text { DPSO, } \\
29 \%(30 / 104)-87 \%(90 / 104) \geq 10 \\
\text { DPSO in serum }{ }^{25}\end{array}$ & $\begin{array}{l}98 \%(82 / 84)-99 \%(83 / 84) \\
\text { in saliva, } 97 \%(103 / 106)- \\
98 \%(104 / 106) \text { in serum }{ }^{25}\end{array}$ \\
\hline & S2 & MFIA & $\begin{array}{l}0 \%(0 / 3)<10 \text { DPSO, } 0 \%(0 / 23) \geq 10 \\
\text { DPSO in saliva; } 4 \%(4 / 92)<10 \\
\text { DPSO, } 30 \%(31 / 104) \geq 10 \text { DPSO in } \\
\text { serum }^{25}\end{array}$ & $\begin{array}{l}99 \%(83 / 84) \text { in saliva, } 97 \% \\
(103 / 106) \text { in serum }^{25}\end{array}$ \\
\hline & ECD & MFIA & $\begin{array}{l}0 \%(0 / 3)<10 \text { DPSO, } 4 \%(1 / 23) \geq 10 \\
\text { DPSO in saliva; } 21 \%(19 / 92)<10 \\
\text { DPSO, } 82 \%(85 / 104) \geq 10 \text { DPSO in } \\
\text { serum }^{25}\end{array}$ & $\begin{array}{l}99 \%(83 / 84) \text { in saliva, } 98 \% \\
(104 / 106) \text { in serum }{ }^{25}\end{array}$ \\
\hline
\end{tabular}


Table S1. Continued.

\begin{tabular}{|c|c|c|c|c|}
\hline Antibody & Antigen & Method & $\begin{array}{l}\text { Sensitivity or positive } \\
\text { coincidence with RT-PCR }\end{array}$ & $\begin{array}{l}\text { Specificity or negative } \\
\text { coincidence with RT-PCR }\end{array}$ \\
\hline \multirow[t]{7}{*}{ IgM } & $\mathrm{S}$ & ELISA & $\begin{array}{l}77.1 \%(165 / 214)^{6} \\
92.3 \%(60 / 65)^{14}\end{array}$ & $100 \%(100 / 100)^{6}$ \\
\hline & $\begin{array}{l}\text { Peptide } \\
\text { from S }\end{array}$ & $\begin{array}{l}\text { MCLIA or } \\
\text { CMIA }\end{array}$ & $57.2 \%(158 / 276)^{32}$ & $100 \%(167 / 167)^{32}$ \\
\hline & $\mathrm{N} / \mathrm{RBD}$ & LFIA or ICG & $84 \%(36 / 43)^{19}$ & $100 \%(40 / 40)^{19}$ \\
\hline & $\mathrm{N} / \mathrm{S}$ & LFIA or ICG & $87.8 \%{ }^{19}$ & $100 \%(40 / 40)^{19}$ \\
\hline & & MCLIA or & $48.1 \%(13 / 27)^{34}$ & $94 \%{ }^{19}$ \\
\hline & & CMIA & $67 \%(243 / 363)^{33}$ & $100 \%(33 / 33)^{34}$ \\
\hline & & & $84 \%(36 / 43)^{19}$ & \\
\hline \multirow[t]{12}{*}{$\operatorname{IgA}$} & $\mathrm{N}$ & ELISA & $84.6 \%(55 / 65)^{14}$ & \\
\hline & & MFIA & $33 \%(1 / 3)<10$ DPSO, $39 \%(9 / 23)-$ & $96 \%(/ 83)-98 \%(/ 83)$ in \\
\hline & & & $48 \%(11 / 23) \geq 10$ DPSO in saliva; & saliva, 98\% (104/106)-99\% \\
\hline & & & $24 \%(22 / 92)-42 \%(39 / 92)<10$ & $(105 / 106)$ in serum ${ }^{25}$ \\
\hline & & & DPSO, 76\% (79/104)-90\% (94/104) & \\
\hline & & & $\geq 10$ DPSO in serum ${ }^{25}$ & \\
\hline & & & $93.3 \%(194 / 208)^{7}$ & \\
\hline & $\mathrm{RBD}$ & MFIA & $0 \%(0 / 3)<10$ DPSO, $17 \%(4 / 23)-$ & $96 \%(80 / 83)-99 \%(82 / 83)$ \\
\hline & & & $30 \%(7 / 23) \geq 10$ DPSO in saliva; & in saliva, $97 \%(103 / 106)-$ \\
\hline & & & $35 \%(32 / 92)-45 \%(41 / 92)<10$ & $99 \%(105 / 106)$ in serum ${ }^{25}$ \\
\hline & & & DPSO, 87\% (90/104)-95\% (99/104) & \\
\hline & & & $\geq 10$ DPSO in serum ${ }^{25}$ & \\
\hline
\end{tabular}


Table S1. Continued.

\begin{tabular}{|c|c|c|c|c|}
\hline Antibody & Antigen & Method & $\begin{array}{l}\text { Sensitivity or positive } \\
\text { coincidence with RT-PCR }\end{array}$ & $\begin{array}{l}\text { Specificity or negative } \\
\text { coincidence with RT-PCR }\end{array}$ \\
\hline \multirow[t]{18}{*}{$\operatorname{IgA}$} & RBD & ELISA & $72.3 \%(47 / 65)^{14}$ & \\
\hline & S1 & ELISA & $46.2 \%(12 / 26) \dagger^{22}$ & $93 \%(105 / 113)^{28}$ \\
\hline & & & $78 \%(86 / 110)^{28}$ & $93.7 \%(192 / 205)^{17}$ \\
\hline & & & $97 \%(73 / 75)^{26}$ & $94 \%(147 / 157)^{26}$ \\
\hline & & MFIA & $0 \%(0 / 3)-33 \%(1 / 3)<10$ DPSO, 8.7 & $42 \%(35 / 83)-100 \%(83 / 83)$ \\
\hline & & & $(2 / 23)-44 \%(10 / 23) \geq 10$ DPSO in & in saliva, $98 \%(104 / 106)-$ \\
\hline & & & saliva; $0 \%(0 / 92)-6 \%(6 / 92)<10$ & $99 \%(105 / 106)$ in serum ${ }^{25}$ \\
\hline & & & DPSO, $15 \%(16 / 104)-52 \%(54 / 104)$ & \\
\hline & & & $\geq 10$ DPSO in serum ${ }^{25}$ & \\
\hline & $\mathrm{S} 2$ & MFIA & $0 \%(0 / 3)<10$ DPSO, $4 \%(1 / 23) \geq 10$ & $100 \%(83 / 83)$ in saliva, \\
\hline & & & DPSO in saliva; $23 \%(21 / 92)<10$ & $99 \%(105 / 106)$ in serum ${ }^{25}$ \\
\hline & & & DPSO, $71 \%(74 / 104) \geq 10$ DPSO in & \\
\hline & & & serum $^{25}$ & \\
\hline & ECD & MFIA & $33 \%(1 / 3)<10$ DPSO, $61 \%(14 / 23)$ & $99 \%(82 / 83)$ in saliva, $96 \%$ \\
\hline & & & $\geq 10$ DPSO in saliva; $36 \%(33 / 92)$ & $(102 / 106)$ in serum ${ }^{25}$ \\
\hline & & & $<10$ DPSO, $90 \%(94 / 104) \geq 10$ & \\
\hline & & & DPSO in serum ${ }^{25}$ & \\
\hline & S & ELISA & $93.8 \%(61 / 65)^{14}$ & \\
\hline
\end{tabular}


Table S1. Continued.

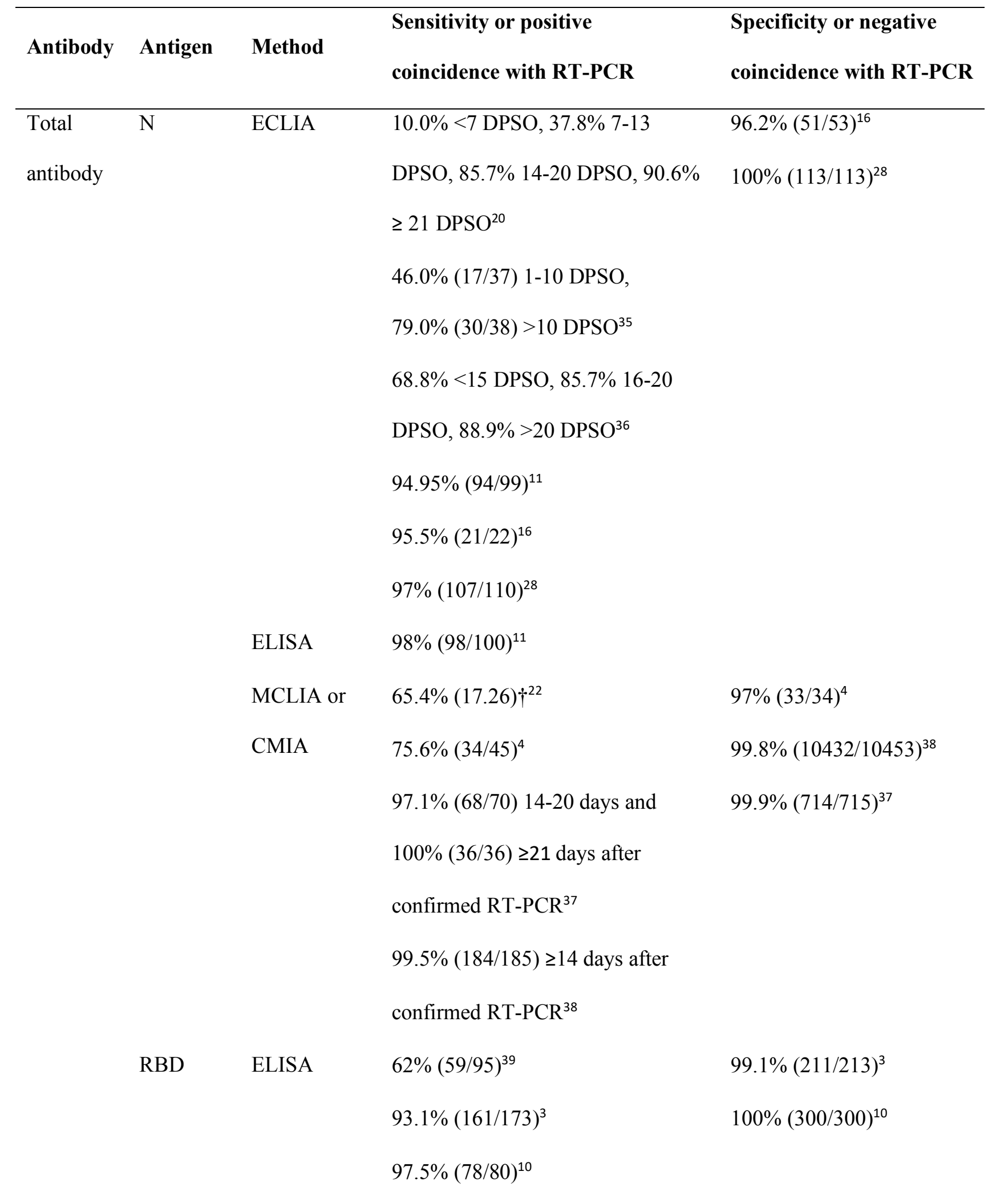


Table S1. Continued.

\begin{tabular}{|c|c|c|c|c|}
\hline Antibody & Antigen & Method & $\begin{array}{l}\text { Sensitivity or positive } \\
\text { coincidence with RT-PCR }\end{array}$ & $\begin{array}{l}\text { Specificity or negative } \\
\text { coincidence with RT-PCR }\end{array}$ \\
\hline \multirow[t]{5}{*}{$\begin{array}{l}\text { Total } \\
\text { antibody }\end{array}$} & RBD & LFIA or ICG & $\begin{array}{l}4 \%(2 / 49), 52 \%(12 / 23), 65 \% \\
(13 / 20)^{40} \\
88.78 \%(87 / 99)^{11} \\
97.5 \%(78 / 80)^{10}\end{array}$ & $95.2 \%(199 / 209)^{10}$ \\
\hline & & $\begin{array}{l}\text { MCLIA or } \\
\text { CMIA }\end{array}$ & $96.3 \%(77 / 80)^{10}$ & $99.3 \%(298 / 300)^{10}$ \\
\hline & $\mathrm{RBD} / \mathrm{S} 1$ & LFIA or ICG & $86.89 \%(106 / 122)^{41}$ & $\begin{array}{l}100 \%(41 / 41) \text { in health } \\
\text { serum, } 99.39 \%(656 / 660) \\
\text { in RT-PCR negative } \\
\text { serum }^{41}\end{array}$ \\
\hline & $\mathrm{S} 1 / \mathrm{S} 2 / \mathrm{N}$ & $\begin{array}{l}\text { Protein } \\
\text { microarrays }\end{array}$ & $79 \%(76 / 96)^{42}$ & $100 \%(47 / 47)^{42}$ \\
\hline & S & $\begin{array}{l}\text { MCLIA or } \\
\text { CMIA }\end{array}$ & $81 \%(134 / 165)^{26}$ & $90 \%(119 / 132)^{26}$ \\
\hline \multirow[t]{8}{*}{$\operatorname{IgG/IgM~}$} & M & ELISA & $83.0 \%(127 / 153)^{43}$ & $96.7(116 / 120)^{43}$ \\
\hline & $\mathrm{N}$ & LFIA or ICG & $90 \%(102 / 113)^{26}$ & $85 \%(83 / 98)^{26}$ \\
\hline & RBD & LFIA or ICG & $88.7 \%(352 / 397)^{44}$ & $90.6 \%(116 / 128)^{44}$ \\
\hline & $\mathrm{N} / \mathrm{S}$ & LFIA or ICG & $99 \%(97 / 98)-$ & $88 \%$ (87/98)- \\
\hline & & & $100 \%(113 / 113)^{26}$ & $89 \%(101 / 113)^{26}$ \\
\hline & Unreported & LFIA or ICG & $62.5 \%(10 / 16) 5-9$ days, $93.8 \%$ & $88.9 \%(24 / 27)^{45}$ \\
\hline & & & $(15 / 16) 10-18$ days after confirmed & $90.9 \%(10 / 11)^{46}$ \\
\hline & & & $\mathrm{PCR}^{31}$ & $91.7 \%(11 / 12)^{47}$ \\
\hline
\end{tabular}


Table S1. Continued.

\begin{tabular}{lllll}
\hline Antibody & Antigen & Method & $\begin{array}{l}\text { Sensitivity or positive } \\
\text { coincidence with RT-PCR }\end{array}$ & $\begin{array}{c}\text { Specificity or negative } \\
\text { coincidence with RT-PCR }\end{array}$ \\
\hline IgG/IgM & Unreported & LFIA or ICG & $11.1 \%(3 / 27)$ in the $1^{\text {st }}$ week, & $100 \%(13 / 13)^{31}$ \\
& $92.9 \%(26 / 28)$ in the $2^{\text {nd }}$ week, & $100 \%(42 / 42)^{48}$ \\
& $96.8 \%(30 / 31) \geq 15 \mathrm{DPSO}^{46}$ & \\
& $18.4 \%(7 / 38)^{47}$ \\
& $36.4 \%(8 / 22)^{45}$ & \\
& $92.93 \%(92 / 99)^{11}$ & \\
& $93.4 \%(99 / 106)^{48}$ & \\
& &
\end{tabular}

Note: ELISA, enzyme-linked immunosorbent assay; LFIA, colloidal-gold lateral-flow immunoassays; ICG, immunochromatographic assays; MCLIA, magnetic particle-based chemiluminescence immunoassay; CMIA, chemiluminescent microparticle immunoassay; MFIA, magnetic particle-based fluorescent immunoassay; ECLIA, electrochemiluminescence immunoassay; ECD, ectodomain protein containing the S1 and S2 subunits of the S protein; $\Delta \mathrm{N}-\mathrm{N}, \mathrm{N}$-terminally truncated nucleocapsid protein; DPSO, day post-symptom onset.

$\dagger$, compared with neutralization test; $\ddagger$, compared with immunofluorescence assay. 
Table S2. The time of detecting antibodies after symptom onset.

\begin{tabular}{|c|c|c|c|c|}
\hline Time & $\begin{array}{l}\text { Total } \\
\text { antibodies }\end{array}$ & $\operatorname{Ig} \mathbf{A}$ & IgM & IgG \\
\hline Median time of & $11 d^{3}$ & $5 \mathrm{~d}(\mathrm{IQR} 3-6)^{7}$ & $5 \mathrm{~d}(\mathrm{IQR} 3-6)^{7}$ & $8-10 d^{50}$ \\
\hline \multirow[t]{6}{*}{ seroconversion } & $9 d^{10}$ & $13 d^{49}$ & $8-10 d^{50}$ & $11 \mathrm{~d}(\mathrm{IQR} 6-18)^{51}$ \\
\hline & & & $10 \mathrm{~d}^{10}$ & $12 \mathrm{~d}^{10}$ \\
\hline & & & $12 d^{3}$ & $13 d^{33}$ \\
\hline & & & $13 \mathrm{~d}^{33}$ & $14 d^{3.49}$ \\
\hline & & & $14 d^{49}$ & $14 d(\text { IQR } 10-18)^{7}$ \\
\hline & & & $14 \mathrm{~d}(\mathrm{IQR} 8-28)^{51}$ & \\
\hline Persistence & & $\sim 2$ months ${ }^{14.27}$ & $\sim 2$ months ${ }^{14.27}$ & $>3$ months $s^{14.27}$ \\
\hline \multirow[t]{7}{*}{ Time of highest titer } & $14 \mathrm{~d}^{10}$ & $2^{\text {nd }}$ week $^{7}$ & $10-12 d^{52.53}$ & $16-20 d^{6}$ \\
\hline & & $16-30 d^{27}$ & $2^{\text {nd }}$ week $^{7.54 .55}$ & $16-30 d^{27}$ \\
\hline & & $20-22 d^{53}$ & $18 \mathrm{~d}^{51}$ & $3^{\text {rd }}$ week $^{54}$ \\
\hline & & & $16-20 d^{6}$ & $4^{\text {th }}$ week $^{33.55}$ \\
\hline & & & $16-30 d^{27}$ & $\geq 21 d^{7}$ \\
\hline & & & $3^{\text {rd }}$ week $^{33}$ & $\geq 25 \mathrm{~d}^{52.53}$ \\
\hline & & & & $30 d^{51}$ \\
\hline Time of highest & $15-21 d^{3}$ & $\geq 12 \mathrm{~d}^{53}$ & $\underline{15 d^{50}}$ & $\geq 12 \mathrm{~d}^{52.53}$ \\
\hline \multirow[t]{4}{*}{ positive rate } & & & $16 d^{3}$ & $15 d^{50}$ \\
\hline & & & $18-19 d^{52.53}$ & $16 d^{3}$ \\
\hline & & & $20-22 d^{33}$ & $\geq 17 \mathrm{~d}^{33}$ \\
\hline & & & $28 d^{5}$ & $49 d^{5}$ \\
\hline
\end{tabular}


Table S2. Continued.

\begin{tabular}{|c|c|c|c|c|}
\hline Time & $\begin{array}{l}\text { Total } \\
\text { antibodies }\end{array}$ & $\operatorname{IgA}$ & IgM & IgG \\
\hline Time for cumulative & $16 \mathrm{~d}$ for $100 \%$ & & $3^{\text {rd }}$ week for $74 \%$ & $3^{\text {rd }}$ week for $100 \%$ \\
\hline \multirow[t]{5}{*}{ positive rate } & $(80 / 80)^{10}$ & & $(28 / 38)^{54}$ & $(38 / 38)^{54}$ \\
\hline & $25 \mathrm{~d}$ for $99 \%$ & & $21 \mathrm{~d}$ for $100 \%$ & $29 \mathrm{~d}$ for $97 \%$ \\
\hline & $(172 / 173)^{3}$ & & $(80 / 80)^{10}$ & $(78 / 80)^{10}$ \\
\hline & & & $30 \mathrm{~d}$ for $99 \%$ & $35 d$ for $99 \%$ \\
\hline & & & $(172 / 173)^{3}$ & $(172 / 173)^{3}$ \\
\hline Time of overtaking & & $\geq 9 \mathrm{~d}^{3}$ & $\geq 10 \mathrm{~d}^{3}$ & $\geq 10 \mathrm{~d}^{3}$ \\
\hline PCR sensitivity & & & $\geq 2$ weeks $^{56}$ & $\geq 2$ weeks $^{56}$ \\
\hline
\end{tabular}

Note: IQR, interquartile range.

\section{References}

(1) Lin, D.; Liu, L.; Zhang, M.; Hu, Y.; Yang, Q.; Guo, J.; Dai, Y.; Xu, Y.; Cai, Y.; Chen, X.; et al. Evaluations of the serological test in the diagnosis of 2019 novel coronavirus (SARS-CoV-2) infections during the COVID-19 outbreak. Eur. J. Clin. Microbiol. Infect. Dis. 2020, 39, 2271-2277.

(2) To, K. K.-W.; Cheng, V. C.-C.; Cai, J.-P.; Chan, K.-H.; Chen, L.-L.; Wong, L.-H.; Choi, C. Y.-K.; Fong, C. H.-Y.; Ng, A. C.-K.; Lu, L.; et al. Seroprevalence of SARS-CoV-2 in Hong Kong and in residents evacuated from Hubei province, China: a multicohort study. Lancet Microbe 2020, 1, e111-e118.

(3) Zhao, J.; Yuan, Q.; Wang, H.; Liu, W.; Liao, X.; Su, Y.; Wang, X.; Yuan, J.; Li, T.; Li, J.; et al. Antibody responses to SARS-CoV-2 in patients with novel coronavirus disease 2019. Clin. Infect. Dis. 2020, $71,2027-2034$.

(4) Kohmer, N.; Westhaus, S.; Rühl, C.; Ciesek, S.; Rabenau, H. F. Brief clinical evaluation of six highthroughput SARS-CoV-2 IgG antibody assays. J. Clin. Virol. 2020, 129, 104480.

(5) Tan, W.; Lu, Y.; Zhang, J.; Wang, J.; Dan, Y.; Tan, Z.; He, X.; Qian, C.; Sun, Q.; Hu, Q.; et al. Viral Kinetics and Antibody Responses in Patients with COVID-19. medRxiv, 2020/03/26. https://doi.org/10.1101/2020.03.24.20042382 (accessed on 2020/08/16).

(6) Liu, W.; Liu, L.; Kou, G.; Zheng, Y.; Ding, Y.; Ni, W.; Wang, Q.; Tan, L.; Wu, W.; Tang, S.; et al. Evaluation of Nucleocapsid and Spike Protein-Based Enzyme-Linked Immunosorbent Assays for Detecting Antibodies against SARS-CoV-2. J. Clin. Microbiol. 2020, 58, e00461-20.

(7) Guo, L.; Ren, L.; Yang, S.; Xiao, M.; Chang; Yang, F.; Dela Cruz, C. S.; Wang, Y.; Wu, C.; Xiao, Y.; et al. Profiling Early Humoral Response to Diagnose Novel Coronavirus Disease (COVID-19). Clin. Infect. Dis. 2020, 71, 778-785. 
(8) Xiang, F.; Wang, X.; He, X.; Peng, Z.; Yang, B.; Zhang, J.; Zhou, Q.; Ye, H.; Ma, Y.; Li, H.; et al. Antibody Detection and Dynamic Characteristics in Patients with COVID-19. Clin. Infect. Dis. 2020, 71, 1930-1934.

(9) Krüttgen, A.; Cornelissen, C. G.; Dreher, M.; Hornef, M.; Imöhl, M.; Kleines, M. Comparison of four new commercial serologic assays for determination of SARS-CoV-2 IgG. J. Clin. Virol. 2020, 128, 104394.

(10) Lou, B.; Li, T.-D.; Zheng, S.-F.; Su, Y.-Y.; Li, Z.-Y.; Liu, W.; Yu, F.; Ge, S.-X.; Zou, Q.-D.; Yuan, Q.; et al. Serology characteristics of SARS-CoV-2 infection since exposure and post symptom onset. Eur.

Respir. J. 2020, 56, 2000763.

(11) Weidner, L.; Gänsdorfer, S.; Unterweger, S.; Weseslindtner, L.; Drexler, C.; Farcet, M.; Witt, V.; Schistal, E.; Schlenke, P.; Kreil, T. R.; et al. Quantification of SARS-CoV-2 antibodies with eight commercially available immunoassays. J. Clin. Virol. 2020, 129, 104540.

(12) Zhang, W.; Du, R.-H.; Li, B.; Zheng, X.-S.; Yang, X.-L.; Hu, B.; Wang, Y.-Y.; Xiao, G.-F.; Yan,

B.; Shi, Z.-L.; et al. Molecular and serological investigation of 2019-nCoV infected patients: implication of multiple shedding routes. Emerg. Microbes Infect. 2020, 9, 386-389.

(13) Yamaoka, Y.; Jeremiah, S. S.; Miyakawa, K.; Saji, R.; Nishii, M.; Takeuchi, I.; Ryo, A. Whole nucleocapsid protein of SARS-CoV-2 may cause false positive results in serological assays. Clin. Infect. Dis. 2020, https://doi.org/10.1093/cid/ciaa637.

(14) Seow, J.; Graham, C.; Merrick, B.; Acors, S.; Pickering, S.; Steel, K. J. A.; Hemmings, O.; O’Byrne, A.; Kouphou, N.; Galao, R. P.; et al. Longitudinal observation and decline of neutralizing antibody responses in the three months following SARS-CoV-2 infection in humans. Nat. Microbiol. 2020, 5, 15981607.

(15) To, K. K.-W.; Tsang, O. T.-Y.; Leung, W.-S.; Tam, A. R.; Wu, T.-C.; Lung, D. C.; Yip, C. C.-Y.; Cai, J.-P.; Chan, J. M.-C.; Chik, T. S.-H.; et al. Temporal profiles of viral load in posterior oropharyngeal saliva samples and serum antibody responses during infection by SARS-CoV-2: an observational cohort study. Lancet Infect. Dis. 2020, 20, 565-574.

(16) Krüttgen, A.; Cornelissen, C. G.; Dreher, M.; Hornef, M. W.; Imöhl, M.; Kleines, M. Determination of SARS-CoV-2 antibodies with assays from Diasorin, Roche and IDvet. J. Virol. Methods 2021, 287, 113978.

(17) Okba, N. M. A.; Muller, M. A.; Li, W.; Wang, C.; GeurtsvanKessel, C. H.; Corman, V. M.; Lamers, M. M.; Sikkema, R. S.; de Bruin, E.; Chandler, F. D.; et al. Severe Acute Respiratory Syndrome Coronavirus 2-Specific Antibody Responses in Coronavirus Disease Patients. Emerg. Infect. Dis. 2020, 26, 1478-1488.

(18) Zeng, L.; Li, Y.; Liu, J.; Guo, L.; Wang, Z.; Xu, X.; Song, S.; Hao, C.; Liu, L.; Xin, M.; et al. Rapid, ultrasensitive and highly specific biosensor for the diagnosis of SARS-CoV-2 in clinical blood samples. Mater. Chem. Front. 2020, 4, 2000-2005.

(19) Nuccetelli, M.; Pieri, M.; Grelli, S.; Ciotti, M.; Miano, R.; Andreoni, M.; Bernardini, S. SARS-CoV2 infection serology: a useful tool to overcome lockdown? Cell Death Discov. 2020, 6, 38.

(20) Tan, S. S.; Saw, S.; Chew, K. L.; Wang, C.; Pajarillaga, A.; Khoo, C.; Wang, W.; Mohamed Ali, Z.; Yang, Z.; Huak, C. Y.; et al. Comparative Clinical Evaluation of the Roche Elecsys and Abbott Severe Acute Respiratory Syndrome Coronavirus 2 (SARS-CoV-2) Serology Assays for Coronavirus Disease 2019 (COVID-19). Arch. Pathol. Lab. Med. 2020, 145, 32-38.

(21) Phipps, W. S.; SoRelle, J. A.; Li, Q.-Z.; Mahimainathan, L.; Araj, E.; Markantonis, J.; Lacelle, C.; Balani, J.; Parikh, H.; Solow, E. B.; et al. SARS-CoV-2 Antibody Responses Do Not Predict COVID-19 Disease Severity. Am. J. Clin. Pathol. 2020, 154, 459-465.

(22) Mueller, L.; Ostermann, P. N.; Walker, A.; Wienemann, T.; Mertens, A.; Adams, O.; Andree, M.; Hauka, S.; Luebke, N.; Keitel, V.; et al. Sensitivity of commercial Anti-SARS-CoV-2 serological assays in a high-prevalence setting. medRxiv, 2020/06/14. https://doi.org/10.1101/2020.06.11.20128686 (accessed on 2020/09/11).

(23) Tang, M. S.; Hock, K. G.; Logsdon, N. M.; Hayes, J. E.; Gronowski, A. M.; Anderson, N. W.; Farnsworth, C. W. Clinical Performance of Two SARS-CoV-2 Serologic Assays. Clin. Chem. 2020, 66, 1055-1062. 
(24) Bryan, A.; Pepper, G.; Wener, M. H.; Fink, S. L.; Morishima, C.; Chaudhary, A.; Jerome, K. R.; Mathias, P. C.; Greninger, A. L. Performance Characteristics of the Abbott Architect SARS-CoV-2 IgG Assay and Seroprevalence in Boise, Idaho. J. Clin. Microbiol. 2020, 58, e00941-20.

(25) Randad, P. R.; Pisanic, N.; Kruczynski, K.; Manabe, Y. C.; Thomas, D.; Pekosz, A.; Klein, S.; Betenbaugh, M. J.; Clarke, W. A.; Laeyendecker, O.; et al. COVID-19 serology at population scale: SARSCoV-2-specific antibody responses in saliva. J. Clin. Microbiol. 2020, https://doi.org/10.1128/JCM.02204-20. (26) GeurtsvanKessel, C. H.; Okba, N. M. A.; Igloi, Z.; Bogers, S.; Embregts, C. W. E.; Laksono, B. M.; Leijten, L.; Rokx, C.; Rijnders, B.; Rahamat-Langendoen, J.; et al. An evaluation of COVID-19 serological assays informs future diagnostics and exposure assessment. Nat. Commun. 2020, 11, 3436.

(27) Isho, B.; Abe, K. T.; Zuo, M.; Jamal, A. J.; Rathod, B.; Wang, J. H.; Li, Z.; Chao, G.; Rojas, O. L.; Bang, Y. M.; et al. Persistence of serum and saliva antibody responses to SARS-CoV-2 spike antigens in COVID-19 patients. Sci. Immunol. 2020, 5, eabe5511.

(28) Kovac, M.; Risch, L.; Thiel, S.; Weber, M.; Grossmann, K.; Wohlwend, N.; Lung, T.; Hillmann, D.; Ritzler, M.; Bigler, S.; et al. EDTA-Anticoagulated Whole Blood for SARS-CoV-2 Antibody Testing by Electrochemiluminescence Immunoassay (ECLIA) and Enzyme-Linked Immunosorbent Assay (ELISA). Diagnostics 2020, 10, 593.

(29) Meyer, B.; Torriani, G.; Yerly, S.; Mazza, L.; Calame, A.; Arm-Vernez, I.; Zimmer, G.; Agoritsas, T.; Stirnemann, J.; Spechbach, H.; et al. Validation of a commercially available SARS-CoV-2 serological immunoassay. Clin. Microbiol. Infect. 2020, 26, 1386-1394.

(30) Rongqing, Z.; Li, M.; Song, H.; Chen, J.; Ren, W.; Feng, Y.; Gao, G. F.; Song, J.; Peng, Y.; Su, B.; et al. Early Detection of Severe Acute Respiratory Syndrome Coronavirus 2 Antibodies as a Serologic Marker of Infection in Patients With Coronavirus Disease 2019. Clin. Infect. Dis. 2020, 71, 2066-2072. (31) Kohmer, N.; Westhaus, S.; Rühl, C.; Ciesek, S.; Rabenau, H. F. Clinical performance of different SARS-CoV-2 IgG antibody tests. J. Med. Virol. 2020, 92, 2243-2247.

(32) Cai, X.-f.; Chen, J.; li Hu, J.; Long, Q.-x.; Deng, H.-j.; Liu, P.; Fan, K.; Liao, P.; Liu, B.-z.; Wu, G.-c.; et al. A Peptide-Based Magnetic Chemiluminescence Enzyme Immunoassay for Serological Diagnosis of Coronavirus Disease 2019. J. Infect. Dis. 2020, 222, 189-193.

(33) Long, Q.-X.; Deng, H.-j.; Chen, J.; Hu, J.; Liu, B.-z.; Liao, P.; Lin, Y.; Yu, L.-h.; Mo, Z.; Xu, Y.-y.; et al. Antibody responses to SARS-CoV-2 in patients with COVID-19. Nat. Med. 2020, 26, 845-848.

(34) Jin, Y.; Wang, M.; Zuo, Z.; Fan, C.; Ye, F.; Cai, Z.; Wang, Y.; Cui, H.; Pan, K.; Xu, A. Diagnostic value and dynamic variance of serum antibody in coronavirus disease 2019. Int. J. Infect. Dis. 2020, 94, 4952.

(35) Pflüger, L. S.; Bannasch, J. H.; Brehm, T. T.; Pfefferle, S.; Hoffmann, A.; Nörz, D.; van der Meirschen, M.; Kluge, S.; Haddad, M.; Pischke, S.; et al. Clinical evaluation of five different automated SARS-CoV-2 serology assays in a cohort of hospitalized COVID-19 patients. J. Clin. Virol. 2020, 130, 104549.

(36) Trabaud, M.-A.; Icard, V.; Milon, M.-P.; Bal, A.; Lina, B.; Escuret, V. Comparison of eight commercial, high-throughput, automated or ELISA assays detecting SARS-CoV-2 IgG or total antibody. $J$. Clin. Virol. 2020, 132, 104613.

(37) Lau, C. S.; Hoo, S. P.; Yew, S. F.; Ong, S. K.; Lum, L. T.; Heng, P. Y.; Tan, J. G.; Wong, M. S.; Aw, T. C. Evaluation of an electrochemiluminescent SARS-CoV-2 antibody assay. J. Appl. Lab. Med. 2020, 5, 1313-1323.

(38) Muench, P.; Jochum, S.; Wenderoth, V.; Ofenloch-Haehnle, B.; Hombach, M.; Strobl, M.; Sadlowski, H.; Sachse, C.; Torriani, G.; Eckerle, I.; et al. Development and Validation of the Elecsys AntiSARS-CoV-2 Immunoassay as a Highly Specific Tool for Determining Past Exposure to SARS-CoV-2. J. Clin. Microbiol. 2020, 58, e01694-20.

(39) Ong, D. S. Y.; de Man, S. J.; Lindeboom, F. A.; Koeleman, J. G. M. Comparison of diagnostic accuracies of rapid serological tests and ELISA to molecular diagnostics in patients with suspected coronavirus disease 2019 presenting to the hospital. Clin. Microbiol. Infect. 2020, 26, 1094.e7-1094.e10. 
(40) Tollånes, M. C.; Bakken Kran, A.-M.; Abildsnes, E.; Jenum, P. A.; Breivik, A. C.; Sandberg, S. Evaluation of eleven rapid tests for detection of antibodies against SARS-CoV-2. Clin. Chem. Lab. Med. 2020, 58, 1595-1600.

(41) Zhang, P.; Gao, Q.; Wang, T.; Ke, Y.; Mo, F.; Jia, R.; Liu, W.; Liu, L.; Zheng, S.; Liu, Y.; et al. Evaluation of recombinant nucleocapsid and spike proteins for serological diagnosis of novel coronavirus disease 2019 (COVID-19). medRxiv, 2020/09/01. https://doi.org/10.1101/2020.03.17.20036954 (accessed on 2020/10/12).

(42) Shaw, A. M.; Hyde, C.; Merrick, B.; James-Pemberton, P.; Squires, B. K.; Olkhov, R. V.; Batra, R.; Patel, A.; Bisnauthsing, K.; Nebbia, G.; et al. Real-world evaluation of a novel technology for quantitative simultaneous antibody detection against multiple SARS-CoV-2 antigens in a cohort of patients presenting with COVID-19 syndrome. Analyst 2020, 145, 5638-5646.

(43) Liu, L.; Liu, W.; Zheng, Y.; Jiang, X.; Kou, G.; Ding, J.; Wang, Q.; Huang, Q.; Ding, Y.; Ni, W.; et al. A preliminary study on serological assay for severe acute respiratory syndrome coronavirus 2 (SARSCoV-2) in 238 admitted hospital patients. Microbes Infect. 2020, 22, 206-211.

(44) Li, Z.; Yi, Y.; Luo, X.; Xiong, N.; Liu, Y.; Li, S.; Sun, R.; Wang, Y.; Hu, B.; Chen, W.; et al. Development and Clinical Application of A Rapid IgM-IgG Combined Antibody Test for SARS-CoV-2 Infection Diagnosis. J. Med. Virol. 2020, 92, 1518-1524.

(45) Döhla, M.; Boesecke, C.; Schulte, B.; Diegmann, C.; Sib, E.; Richter, E.; Eschbach-Bludau, M.; Aldabbagh, S.; Marx, B.; Eis-Hübinger, A. M.; et al. Rapid point-of-care testing for SARS-CoV-2 in a community screening setting shows low sensitivity. Public Health 2020, 182, 170-172.

(46) Pan, Y.; Li, X.; Yang, G.; Fan, J.; Tang, Y.; Zhao, J.; Long, X.; Guo, S.; Zhao, Z.; Liu, Y.; et al. Serological immunochromatographic approach in diagnosis with SARS-CoV-2 infected COVID-19 patients. J. Infect. 2020, 81, e28-e32.

(47) Cassaniti, I.; Novazzi, F.; Giardina, F.; Salinaro, F.; Sachs, M.; Perlini, S.; Bruno, R.; Mojoli, F.; Baldanti, F.; Members of the San Matteo Pavia, C.-T. F. Performance of VivaDiag COVID-19 IgM/IgG Rapid Test is inadequate for diagnosis of COVID-19 in acute patients referring to emergency room department. J. Med. Virol. 2020, 92, 1724-1727.

(48) Dellière, S.; Salmona, M.; Minier, M.; Gabassi, A.; Alanio, A.; Le Goff, J.; Delaugerre, C.; Chaix, M.-L. Evaluation of the COVID-19 IgG/IgM Rapid Test from Orient Gene Biotech. J. Clin. Microbiol. 2020, 58, e01233-20.

(49) Yu, H.-q.; Sun, B.-q.; Fang, Z.-f.; Zhao, J.-c.; Liu, X.-y.; Li, Y.-m.; Sun, X.-z.; Liang, H.-f.; Zhong, B.; Huang, Z.-f.; et al. Distinct features of SARS-CoV-2-specific IgA response in COVID-19 patients. Eur. Respir. J. 2020, 56, 2001526.

(50) Demey, B.; Daher, N.; François, C.; Lanoix, J.-P.; Duverlie, G.; Castelain, S.; Brochot, E. Dynamic profile for the detection of anti-SARS-CoV-2 antibodies using four immunochromatographic assays. J. Infect. 2020, 81 , e6-e10.

(51) Qu, J.; Wu, C.; Li, X.; Zhang, G.; Jiang, Z.; Li, X.; Zhu, Q.; Liu, L. Profile of Immunoglobulin G and IgM Antibodies Against Severe Acute Respiratory Syndrome Coronavirus 2 (SARS-CoV-2). Clin. Infect. Dis. 2020, 71, 2255-2258.

(52) Padoan, A.; Cosma, C.; Sciacovelli, L.; Faggian, D.; Plebani, M. Analytical performances of a chemiluminescence immunoassay for SARS-CoV-2 IgM/IgG and antibody kinetics. Clin. Chem. Lab. Med. 2020, 58, 1081-1088.

(53) Padoan, A.; Sciacovelli, L.; Basso, D.; Negrini, D.; Zuin, S.; Cosma, C.; Faggian, D.; Matricardi, P.; Plebani, M. IgA-Ab response to spike glycoprotein of SARS-CoV-2 in patients with COVID-19: A longitudinal study. Clin. Chim. Acta 2020, 507, 164-166.

(54) Sun, B.; Feng, Y.; Mo, X.; Zheng, P.; Wang, Q.; Li, P.; Peng, P.; Liu, X.; Chen, Z.; Huang, H.; et al. Kinetics of SARS-CoV-2 specific IgM and IgG responses in COVID-19 patients. Emerg. Microbes Infect. 2020, $9,940-948$.

(55) Zhang, B.; Zhou, X.; Zhu, C.; Song, Y.; Feng, F.; Qiu, Y.; Feng, J.; Jia, Q.; Song, Q.; Zhu, B.; et al. Immune Phenotyping Based on the Neutrophil-to-Lymphocyte Ratio and IgG Level Predicts Disease Severity and Outcome for Patients With COVID-19. Front. Mol. Biosci. 2020, 7, 157. 
(56) Yong, G.; Yi, Y.; Tuantuan, L.; Xiaowu, W.; Xiuyong, L.; Ang, L.; Mingfeng, H. Evaluation of the auxiliary diagnostic value of antibody assays for the detection of novel coronavirus (SARS-CoV-2). J. Med. Virol. 2020, 92, 1975-1979. 